Portland State University

PDXScholar

Physics Faculty Publications and Presentations

Physics

2014

\title{
Kinesthetic Activities for the Classroom
}

\author{
Elliot E. Mylott \\ Portland State University \\ Justin C. Dunlap \\ Portland State University \\ Lester Lampert \\ Portland State University \\ Ralf Widenhorn \\ Portland State University
}

Follow this and additional works at: https://pdxscholar.library.pdx.edu/phy_fac

Part of the Physics Commons, and the Science and Mathematics Education Commons

Let us know how access to this document benefits you.

\section{Citation Details}

Mylott, E., Dunlap, J., Lampert, L., \& Widenhorn, R. (2014). Kinesthetic activities for the classroom. The Physics Teacher, 52(9), 525-528.

This Article is brought to you for free and open access. It has been accepted for inclusion in Physics Faculty Publications and Presentations by an authorized administrator of PDXScholar. Please contact us if we can make this document more accessible: pdxscholar@pdx.edu. 


\section{Kinesthetic Activities for the Classroom}

\section{Elliot Mylott, Justin Dunlap, Lester Lampert, and Ralf Widenhorn, Portland State University, Portland, OR}

$\mathrm{E}$ ducators have found that kinesthetic involvement in an experiment or demonstration can engage students in a powerful way. ${ }^{1-3}$ With that as our goal, we developed three activities that allow students to connect with and quantitatively explore key physics principles from mechanics with three fun physical challenges. By presenting these activities as competitions, we can challenge students to use what they know about the relevant physics to improve their performance and beat their own score or those of other students. Each activity uses an original, real-time data collecting program that offers students and educators a simple, clear method to demonstrate various physics concepts including: (1) impulse momentum, (2) center of mass (COM), and (3) kinematics. The user interface, written in LabVIEW, is intuitive to operate and only requires Vernier Force Plates, ${ }^{4}$ a Vernier LabQuest, ${ }^{5}$ a webcam, and a computer. In this article, we will describe each of these activities, all of which are well suited and readily available for other outreach events or classroom demonstrations.

\section{In the classroom and at outreach events}

These activities have been used in multiple formats and venues including in the mechanics section of introductory general physics at Portland State University (PSU) and multiple outreach events both on campus and at local schools by the Science Outreach Society, a student-led PSU group that promotes science literacy in the community. ${ }^{6}$ Although the depth of detail used to discuss the physical principles involved in the activities varied by the setting and age of the group, participants at various venues showed marked engagement with the activities. Often students participated multiple times in the same competition, attempting to employ new strategies building on an evolving understanding of basic physics concepts. The activities were also featured in holiday parties of the PSU physics department. Senior faculty members and students alike embraced the competition aspect of the activities, and actively debated and experimented with different methods to improve their scores. In some cases, discussion of physics-based approaches and practice led to near perfect scores.

\section{Physics of ballet}

The Science Outreach Society at PSU and the Oregon Ballet Theater incorporated these competitions in the presentation "The Physics of Ballet" for the Oregon Museum of Science and Industry's popular outreach series Science Pub. ${ }^{7}$ A similar presentation was given at the 2013 American Association of Physics Teachers (AAPT) Summer Meeting demo show, which is where the photographs in this article were taken. ${ }^{6}$ The connection with dance allowed for a playful engagement with physics and served as an ideal example of how the activities described below can be implemented. Physics and dance may sometimes be thought of as separate disciplines to both the physicist and dancer alike. However, bringing the two together has some direct and latent benefits that can be reaped by both the instructor and student. The merging of physics and dance has the potential to teach and cultivate an appreciation of both fields to a wide and general audience. In a recent Resource Letter to the American Journal of Physics, Laws and Lott point out there are two possible approaches to the integration of physics and dance: "(1) analyzing dance movement using the principles and framework of
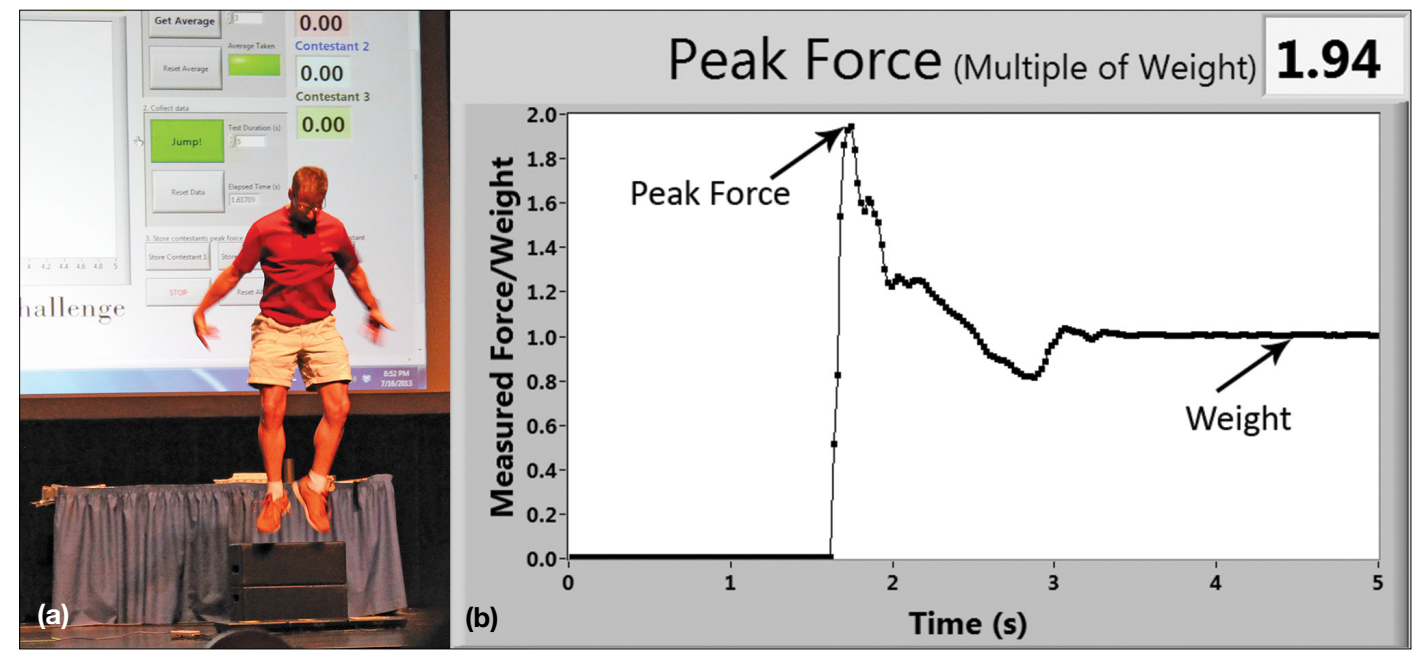

Fig. 1. (a) A volunteer jumps from a small platform onto a force plate. (b) Force plate data of a volunteer jumping off a chair. The volunteer's weight is measured before the jump but not displayed (photo courtesy AAPT). 


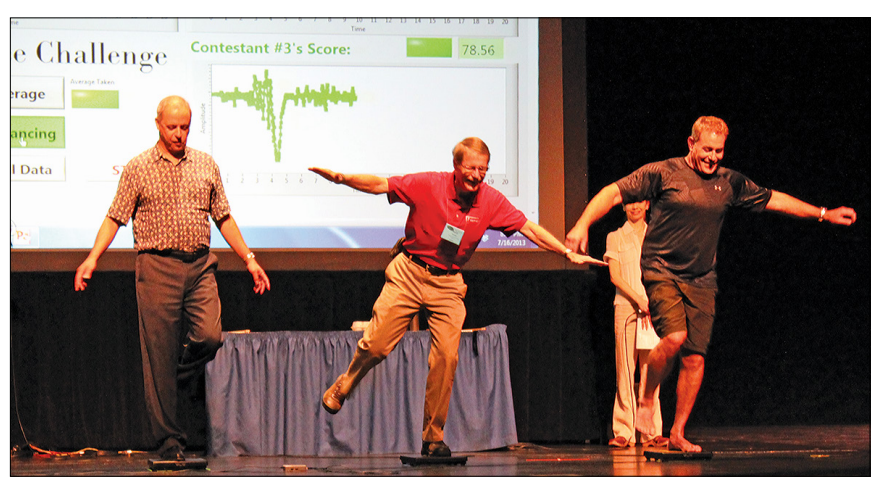

Fig. 2. Three volunteers are asked to balance on one foot with their eyes shut while the force plates measure the stabilizing forces they exert (photo courtesy AAPT).

physics and (2) using dance as a vehicle for portraying and explaining physics." 8 Physicists are able to decompose a system into smaller pieces and fundamentals in order to create a model to explain various principles to students. Dancers adeptly execute movement for the purpose of artistic expression, while at the same time providing striking demonstrations of those same principles. For this reason, it is exciting to create a bridge between the two disciplines, which fosters passion about physics inside and outside the classroom. Of course, it is up to a teacher's creativity to tailor the physical activities to other disciplines and make them fit the interest of the audience.

\section{Impulse momentum}

Many athletic activities including ballet reduce the risk of injury by utilizing a sprung floor or foam mats. By increasing the duration of a landing, sprung floors and mats decrease the peak force felt by the dancer or athlete, as explained by the impulse-momentum theorem. The impulse-momentum theorem states that

$$
F \Delta t=m \Delta \mathrm{v}
$$

To explore this relationship, participants are asked to jump from a small platform onto a force plate. The LabVIEW program plots the measured force from the contestant's landing in real time (Fig. 1). The vertical axis of the plot is the ratio of the measured force, or apparent weight, to the weight of the contestant, which is measured before the jump. In this way contestants' weights remain private and people of different weights have a chance to compete on equal footing. The score represents the peak force of the landing as a multiple of the participant's weight. The contestants are challenged to use the concepts learned from the impulse-momentum theorem to get the lowest score.

Because the contestant ends the collision with the floor at zero velocity, the peak force of the impulse is dependent on the duration of the landing and the contestant's velocity immediately before landing, which itself is a function of the contestant's starting height. In the classroom, students are able to verify these relationships by experimenting with the dependent variables: starting height and landing time. Students can also discuss how a person's height may impact the chances for a low score. For example, students can lower their scores by crouching in the chair before jumping, which lowers their COM toward the floor and decreases their final velocity. They can also lower their scores by increasing the duration of the landing by bending their legs during impact. Experiments testing the efficacy of sprung boards or the foam mats used in gym classes can be performed by placing the mat on the force plate and comparing the peak force with and without the mat. The program easily lends itself to other similar experiments involving running and walking. ${ }^{9}$

\section{Balance challenge}

Dancers, like many athletes, must often maintain good balance in difficult positions. One example of this is dancing en pointe, a ballet technique in which the dancer supports her weight entirely on the tips of her toes. This requires extensive practice, special shoes, and a finely balanced COM. For an object to remain upright, its COM must be above its base of
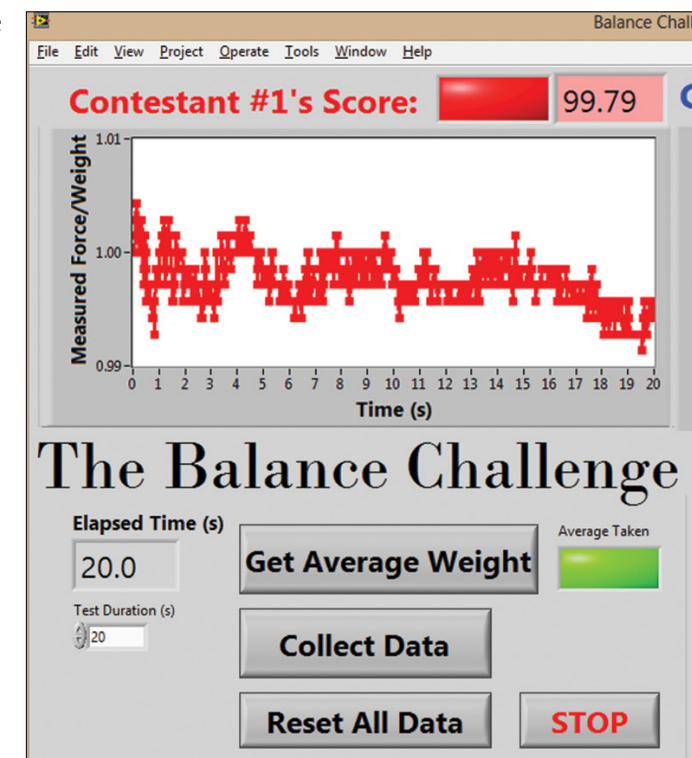

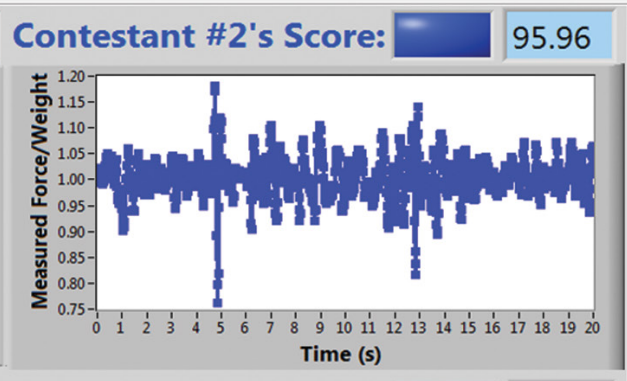

Contestant \#3's Score: 86.23

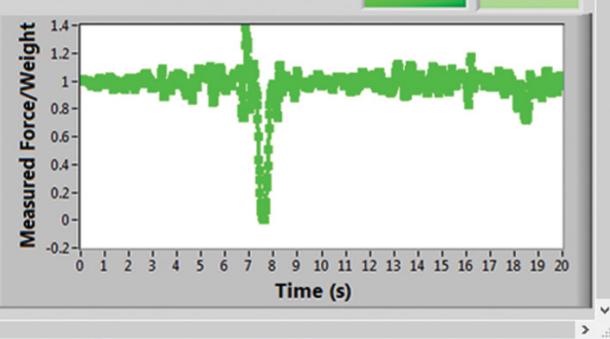

Fig. 3. Screen capture of the LabVIEW program used in the balance challenge. The graphs display the force plate data of three volunteers. Contestant \#1 is balancing on two feet. Contestant \#2 is balancing on one foot with open eyes. Contestant \#3 is balancing on one foot with closed eyes. Note that at approximately $7.5 \mathrm{~s}$ Contestant \#3 lost his balance and stepped off the force plate. 
support. If the base of support is small, staying balanced can be difficult. For example, it is more difficult for a person to balance on one foot than on two, and even more difficult to balance en pointe. By using a force plate, we can measure the vertical component of the stabilizing forces a person exerts while balancing. Like in the previous activity, the ratio of the measured force divided by the person's weight is displayed. This ratio fluctuates as the person tries to maintain balance and the standard deviation is used as a figure of merit. ${ }^{10}$ The smaller the standard deviation of the force plate data, the less a person is adjusting and therefore the better the balance.

In this demonstration, three contestants are each asked to balance on a force plate on one leg and with closed eyes (Fig. 2). The LabVIEW program collects and displays the data from all three force plates in real time.

While the contestants are balancing, their scores are continually being updated according to:

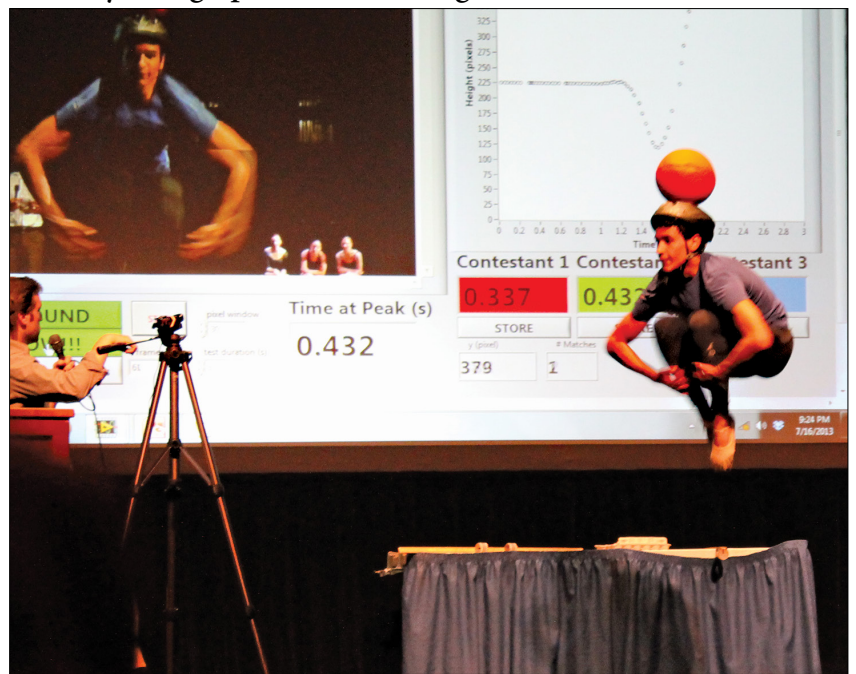

Fig. 4. Jordan Kindell, a dancer from the Oregon Ballet Theater, demonstrates how tucking in his arms and legs while jumping causes his head to deviate from a parabolic trajectory. A foam ball painted orange and attached to a bicycle helmet was used to track the position of his head during the jump. (photo courtesy AAPT).

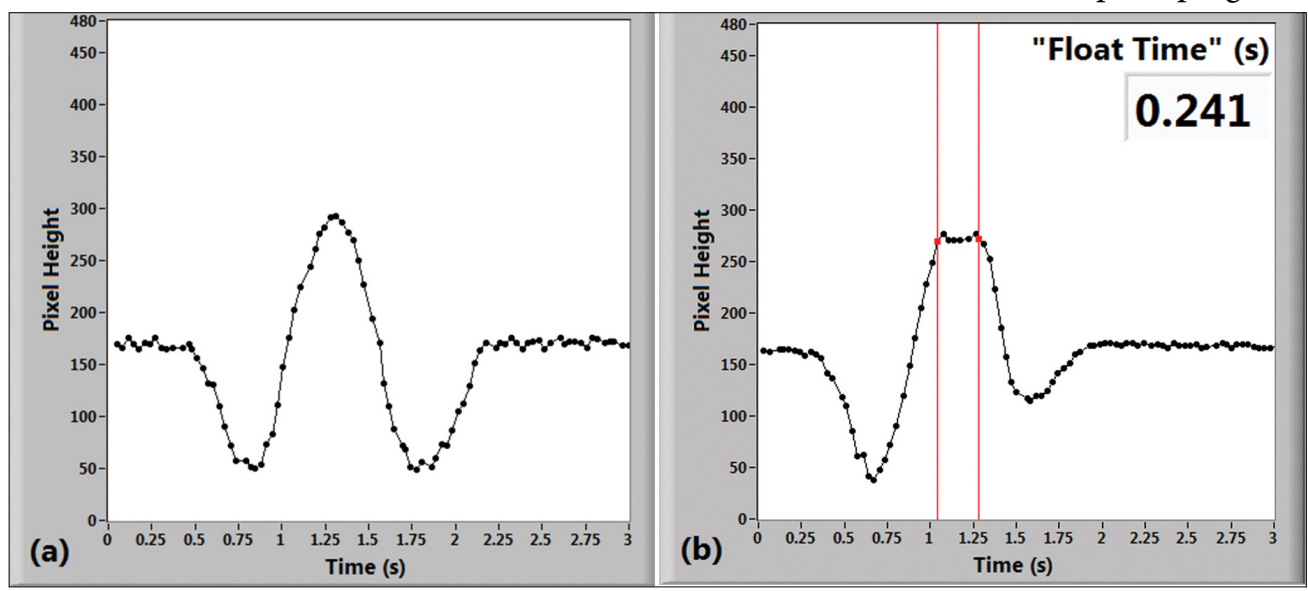

Fig. 5. Trajectory of a ball attached to a helmet worn by the contestant for (a) a normal jump and (b) a jump in which the contestant tucks in his arms and legs. By changing the position of his center of mass, the contestant's head follows a nonparabolic path.

$$
\text { Score }=\frac{\text { weight }-\sigma}{\text { weight }} \times 100 \% \text {, }
$$

where $\sigma$ is the standard deviation of the measured force plate data. The standard deviations are changing as the measurements are updated, which means the scores change in real time during the 20 -second balance challenge.

As a classroom activity, students can experiment with different ways of balancing and immediately visualize the effect upon their scores. For example, one student could stand on two feet while another stands on one foot. Students can also explore the large role that sight plays in helping them balance. Contestants \#2 and \#3 shown in Fig. 3 were both standing on one foot, but Contestant \#3 has a lower score, largely due to his eyes being closed. Contestants may also explore how holding a long pole or a rotating wheel as a gyroscope may help them in maintaining their balance. Besides the discussion of the COM, this contest is a useful way to introduce students to the idea of the standard deviation.

\section{Kinematics}

Once an object leaves the ground, the motion of its $\mathrm{COM}$ will follow a parabolic trajectory. This is even true of an object that is able to change its mass distribution mid-flight, although it may be difficult for an observer to follow the motion of the COM. One such example is when a person moves his arms and legs while jumping, resulting in sections of the body following nonparabolic trajectories. A ballet move called a toe touch involves a dancer jumping up and extending her legs into a split while in the air. By moving her legs up, her COM also rises, which causes her head to lower. After touching her toes, the dancer lowers her legs, which causes her head to rise. When done correctly, the result is a "floating" illusion ${ }^{11}$ in which the dancer's head remains stationary during part of the jump. A similar effect can be seen in another ballet movement called a grand jeté, ${ }^{11}$ where the dancer leaps forward as well as upward.

Video capture programs, which require manually selecting the tracked object in each frame, have had great success in teaching kinematics in a laboratory setting. ${ }^{12,13}$ However, in a live outreach event, data analysis must be available quickly. Our third LabVIEW program is able to track the position of an object in sequential images captured from a webcam and plot its trajectory in real time. We wanted to track the motion of the contestant's head as he attempted the toe touch, so we tasked the program to follow an orange ball attached to a bicycle helmet (Fig. 4); this was both an 
easy target for the program to track and an eye-catching prop for the stage. The program can easily be tasked by the user to follow other indicators, including a spot of colored paper or garment.

For this competition, the contestant's task is to jump while maximizing the duration of the floating effect. The contestants are asked to jump straight up and move their bodies in such a way as to cause the trajectory of their heads to deviate from a parabolic function. Agile and ambitious contestants are invited to attempt the toe touch, but other options are also available-similar results can be achieved by closely tucking one's arms and legs in toward the body while in the air. Figure 5 shows the plots of two jumps: one straight up and down as well as one in which the contestant jumps and tucks in his appendages, as in Fig. 4. The graph in Fig. 5 plots the vertical coordinate of the pixel containing the center of the orange ball. As can be seen in the first plot, the contestant's head is described by a parabolic function while jumping straight up and down. However, in the second plot the contestant is able to achieve the "floating" illusion by tucking in his arms and legs while jumping. The "float" time can be measured using the cursors on the graph.

\section{Summary}

The activities presented in this article offer students and instructors a highly engaging tool for inquiry in motion and mechanics. They use equipment commonly found in physics teaching laboratories and require very little setup. The programs can be downloaded ${ }^{14}$ as executables or as LabVIEW source code for use in outreach events or for more in-depth experimentation and analysis in classroom demonstrations or laboratory activities. These activities offer a simple and powerful platform for classrooms and can be expanded using topics from biomechanics and dance to engage a wide audience.

\section{Acknowledgment}

This work was supported by the TUES grant DUE-1141078 from the National Science Foundation.

\section{References}

1. Priscilla Laws, "Workshop Physics: Learning introductory physics by doing it," Changes 23, 20-27 (July-Aug. 1991).

2. Panagiotis Pantidos and Stamatis Patapis, "Kinesthetic transverse wave demonstration," Phys. Teach. 43, 344-345 (Sept. 2005).

3. Brooke A. Whitworth, Jennifer L. Chiu, and Randy L. Bell, "Kinesthetic investigations in the physics classroom," Phys. Teach. 52, 91-93 (Feb. 2014).

4. Vernier Force Plate, FP-BTA, http://www.vernier.com/ products/sensors/force-sensors/fp-bta/.

5. Vernier LabQuest Mini, LQ-MINI, http://www.vernier.com/ products/interfaces/lq-mini/.

6. Science Outreach Society, http://scienceoutreachsociety. weebly.com/.
7. Oregon Museum of Science and Industry Science Pub, http:// www.omsi.edu/sciencepub.

8. Kenneth Laws and Melanie Lott, "Resource Letter PoD-1: The physics of dance," Am. J. Phys. 81, 7-13 (Jan. 2013).

9. Rod Cross, "Standing, walking, running, and jumping on a force plate," Am. J. Phys. 67, 304-309 (April 1999).

10. Annica Önell, "The vertical ground reaction force for analysis of balance?” Gait and Posture 12, 7-13 (2000).

11. Kenneth Laws, Physics and the Art of Dance: Understanding Movement, 2nd ed. (Oxford University Press, New York, 2008), pp. 52-54.

12. Priscilla Laws and Hans Pfister, "Using digital video analysis in introductory mechanics projects," Phys. Teach. 36, 282-287 (May 1998).

13. Edward P. Wyrembeck, "Video analysis with a web camera," Phys. Teach. 47, 28-29 (Jan. 2009).

14. http://web.pdx.edu/ ralfw/motion-analysis.html.

Portland State University, Portland, OR 97201; emylott@pdx.edu

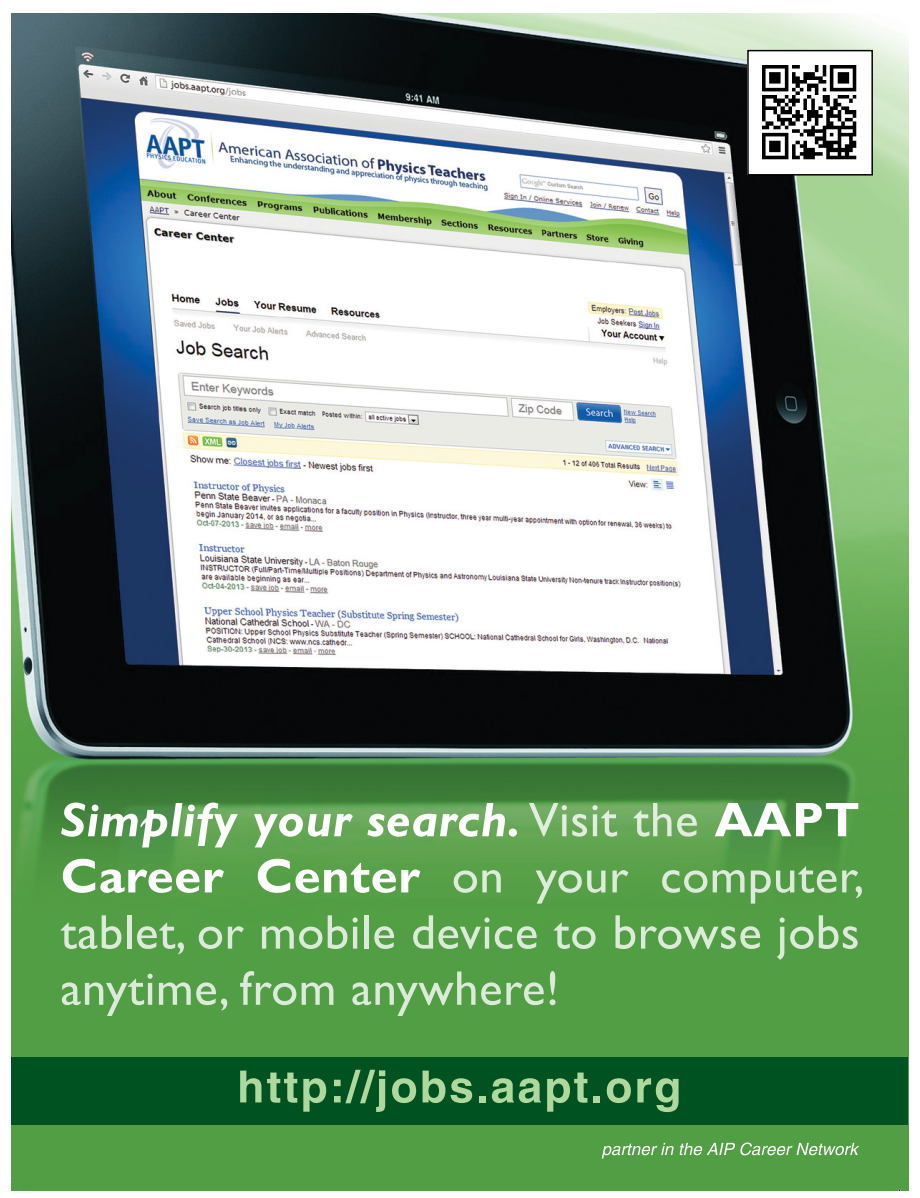

